\title{
Solvent Blending Strategy to Upgrade MCU CSSX Solvent to Equivalent Next- Generation CSSX Solvent
}

December 2012

\author{
Prepared by
}

Lætitia H. Delmau and Bruce A. Moyer 


\section{DOCUMENT AVAILABILITY}

Reports produced after January 1, 1996, are generally available free via the U.S. Department of Energy (DOE) Information Bridge.

Web site http://www.osti.gov/bridge

Reports produced before January 1, 1996, may be purchased by members of the public from the following source.

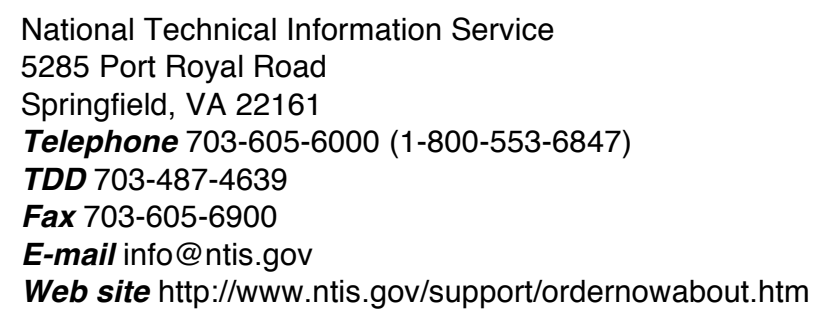

Reports are available to DOE employees, DOE contractors, Energy Technology Data Exchange (ETDE) representatives, and International Nuclear Information System (INIS) representatives from the following source.

Office of Scientific and Technical Information

P.O. Box 62

Oak Ridge, TN 37831

Telephone 865-576-8401

Fax 865-576-5728

E-mail reports@osti.gov

Web site http://www.osti.gov/contact.html

This report was prepared as an account of work sponsored by an agency of the United States Government. Neither the United States Government nor any agency thereof, nor any of their employees, makes any warranty, express or implied, or assumes any legal liability or responsibility for the accuracy, completeness, or usefulness of any information, apparatus, product, or process disclosed, or represents that its use would not infringe privately owned rights. Reference herein to any specific commercial product, process, or service by trade name, trademark, manufacturer, or otherwise, does not necessarily constitute or imply its endorsement, recommendation, or favoring by the United States Government or any agency thereof. The views and opinions of authors expressed herein do not necessarily state or reflect those of the United States Government or any agency thereof. 
Next-Generation CSSX Program

\section{SOLVENT BLENDING STRATEGY TO UPGRADE MCU CSSX SOLVENT TO EQUIVALENT NEXT-GENERATION CSSX SOLVENT}

Lætitia H. Delmau and Bruce A. Moyer

Date Published: December 2012

Prepared by

OAK RIDGE NATIONAL LABORATORY

Oak Ridge, Tennessee 37831-6283

managed by

UT-BATTELLE, LLC

for the

U.S. DEPARTMENT OF ENERGY

under contract DE-AC05-00OR22725 



\section{CONTENTS}

Page

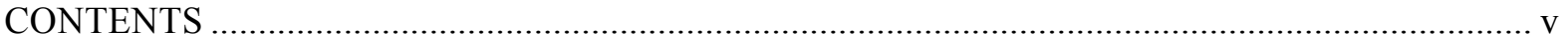

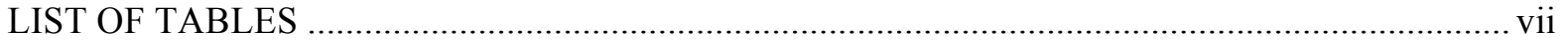

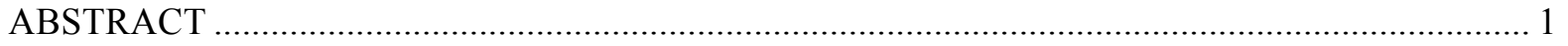

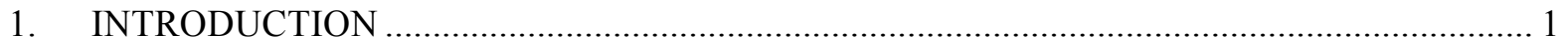

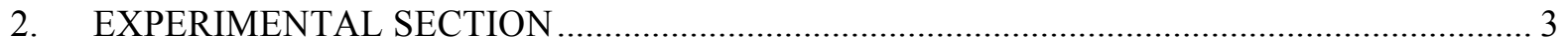

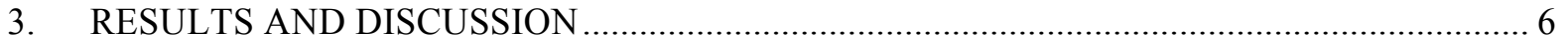

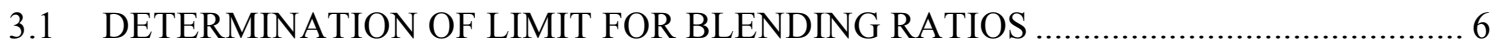

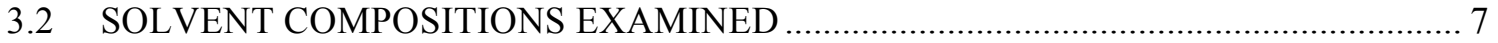

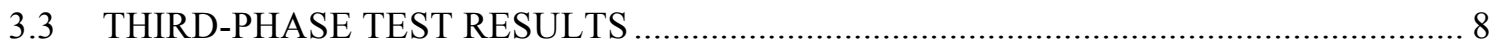

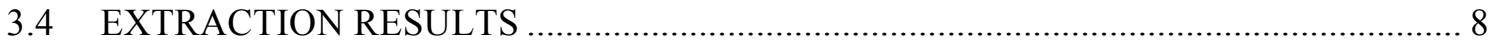

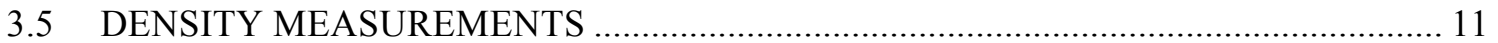

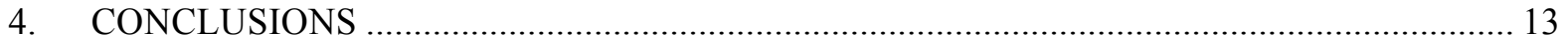

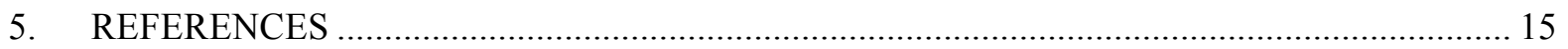





\section{LIST OF TABLES}

Page

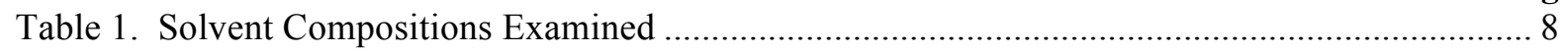

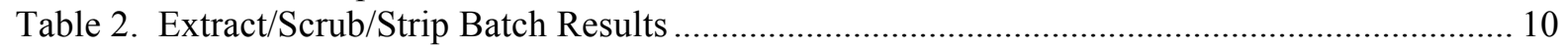

Table 3. Linear Regression Parameters for Dependence of Cesium Distribution Ratio on Solvent

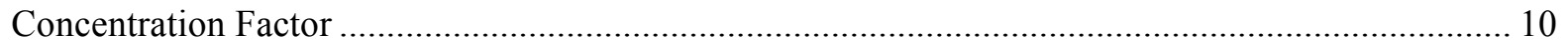

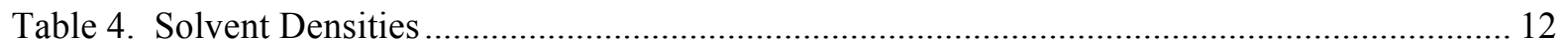





\begin{abstract}
The results of the present study have validated an equal-volume blending strategy for upgrading freshly prepared CSSX solvent to a blended solvent functionally equivalent to NG-CSSX solvent. It is shown that blending fresh CSSX solvent as currently used in MCU with an equal volume of an NG-CSSX solvent concentrate of appropriate composition yields a blended solvent composition (46.5 mM of MaxCalix, 3.5 $\mathrm{mM}$ of BOBCalixC6, $0.5 \mathrm{M}$ of Cs-7SB, $3 \mathrm{mM}$ of guanidine suppressor, and $1.5 \mathrm{mM}$ of TOA in Isopar L) that exhibits equivalent batch ESS performance to that of the NG-CSSX solvent containing $50 \mathrm{mM}$ of MaxCalix, $0.5 \mathrm{M}$ of $\mathrm{Cs}-7 \mathrm{SB}$, and $3 \mathrm{mM}$ of guanidine suppressor in Isopar L. The solvent blend composition is robust to third-phase formation. Results also show that a blend containing up to $60 \% \mathrm{v} / \mathrm{v}$ of CSSX solvent could be accommodated with minimal risk. Extraction and density data for the effect of solvent concentration mimicking diluent evaporation or over-dilution of the equal-volume blended solvent are also given, providing input for setting operational limits. Given that the experiments employed all pristine chemicals, the results do not qualify a blended solvent starting with actual used MCU solvent, which can be expected to have undergone some degree of degradation. Consequently, further work should be considered to evaluate this risk and implement appropriate remediation if needed.
\end{abstract}

\title{
1. INTRODUCTION
}

This report presents the results obtained in support of developing a blending strategy to upgrade the used solvent inventory in the Modular Caustic Side Solvent Extraction (CSSX) Unit (MCU) with solvent components recommended for the Next Generation CSSX (NG-CSSX) process. In the latter part of 2012, the MCU will begin a transition from the baseline CSSX process to the NG-CSSX process (also known as Next Generation Solvent or NGS). Under the expectation that the components of the CSSX process are compatible with those of the NG-CSSX process, a significant cost savings could be achieved by implementing a blending strategy in which components of the NG-CSSX are added directly to the existing inventory of the MCU in such a way that the resulting new solvent inventory is the equivalent of the NG-CSSX solvent composition. The NG-CSSX process has been recently described along with the function of each solvent component [1].

The current recommendation to reach the target cesium decontamination and concentration factors $(\mathrm{DF}=$ 40,000 and $\mathrm{CF}=15$ ) for $\mathrm{MCU}$ is to use a solvent containing $50 \mathrm{mM}$ of MaxCalix, 0.5 M of modifier Cs$7 \mathrm{SB}$, and $3 \mathrm{mM}$ of guanidine suppressor (Gua) in Isopar ${ }^{\circledR} \mathrm{L}$ [1]. At the start of the transition to NG- 
CSSX, approximately 100 gal of used CSSX solvent is expected to remain in the MCU inventory, consisting of $7 \mathrm{mM}$ BOBCalixC6, $0.75 \mathrm{M} \mathrm{Cs}-7 \mathrm{SB}$, and $3 \mathrm{mM}$ tri- $n$-octylamine in Isopar L (TOA). Assuming a solvent upgrade to a final 200 gal inventory of NG-CSSX solvent, a blending strategy will lead to a mixture of $3.5 \mathrm{mM}$ BOBCalixC6 and $46.5 \mathrm{mM}$ MaxCalix as the effective cesium extractant and a mixture of $3 \mathrm{mM}$ Gua and $1.5 \mathrm{mM}$ TOA as the suppressor, in Isopar L diluent modified with $0.5 \mathrm{M}$ Cs7SB. Regarding the suppressor, the residual TOA is considered inert, as it was demonstrated that the 10 $\mathrm{mM}$ boric acid stripping solutions are not acidic enough to allow TOA to perform efficiently as a suppressor [2]. Thus, we will employ a final concentration of Gua of $3 \mathrm{mM}$. On the contrary, regarding the cesium extractants, it is known that BOBCalixC6 is slightly more powerful than MaxCalix; therefore, its final concentration will be taken into account so that the total concentration of calixarene equals 50 $\mathrm{mM}$.

Data are presented herein to qualify the above-described blended solvent composition in terms of solubility behavior and cesium distribution in batch testing with simulated SRS waste. Initial tests were carried out to ensure that it is possible to prepare an initial homogeneous concentrated makeup solution consisting of, for example, $100 \mathrm{mM}$ of MaxCalix, $0.25 \mathrm{M}$ of Cs-7SB, and $6 \mathrm{mM}$ of Gua in Isopar L. The final blended composition tested was $46.5 \mathrm{mM}$ of MaxCalix, $3.5 \mathrm{mM}$ of BOBCalixC6, 0.5 M of Cs-7SB, $3 \mathrm{mM}$ of Gua, and $1.5 \mathrm{mM}$ of TOA in Isopar L. More- or less-concentrated blend variants with different amounts of Isopar L were also tested to examine effects of diluent evaporation and makeup. Once blend solutions were prepared, third-phase formation tests and extraction/scrub/strip (ESS) experiments were run. Densities of corresponding solvents were also measured.

While the data in fact support a simple solvent-blending strategy with no issues regarding solubility or cesium distribution, it should be recognized that the results do not qualify an actual blended solvent starting with used MCU solvent. Impurities in the used MCU solvent may have unanticipated effects in the performance of the NG-CSSX flowsheet. 


\section{EXPERIMENTAL SECTION}

The following solvent components were used as received: Calix[4]arene-bis(tert-octylbenzocrown-6) (BOBCalixC6) was obtained from IBC Advanced Technologies. 1-(2,2,3,3-Tetrafluoropropoxy)-3-[4(sec-butyl)phenoxy]-2-propanol (Cs-7SB modifier), and 1,3-alt-25,27-bis(3,7dimethyloctyloxy)calix[4]arene-benzocrown-6 (MaxCalix) were obtained from Marshallton Research. Tri- $n$-octylamine (TOA) was obtained from Aldrich, and Isopar ${ }^{\circledR} \mathrm{L}$ was obtained from ExxonMobil. The guanidine suppressor (Gua) was synthesized according to a recent report [3] and publication [4].

Unless otherwise specified, solvent solutions were prepared by weighing solvent components into volumetric flasks and diluting with Isopar L. All solvents were prewashed prior to use in the following manner: one contact sequentially with $0.010 \mathrm{M} \mathrm{HCl}, \mathrm{H}_{2} \mathrm{O}$, then decreasing concentrations of $\mathrm{NaOH}(0.3$ $\mathrm{M}, 0.1 \mathrm{M}, 0.03 \mathrm{M}$, and $0.01 \mathrm{M}$ ), and then once or twice with $\mathrm{H}_{2} \mathrm{O}$ until the solution was $\mathrm{pH}$ neutral.

The waste simulant SRS-15 represents an average SRS salt waste with multiple inorganic and organic components, including $15 \mathrm{mM}$ of potassium. It was prepared following a recipe described previously [5]. An analogous simulant, SRS-45, containing $45 \mathrm{mM}$ potassium but with the same composition as SRS-15 [5] was also prepared. This level of potassium is considered the upper limit for SRS salt waste.

Third-phase formation experiments were conducted in a refrigerated incubator in which was placed a NIST-traceable thermometer. A sample of blended solvent composed of $46.5 \mathrm{mM}$ of MaxCalix, $3.5 \mathrm{mM}$ of BOBCalixC6, $0.5 \mathrm{M}$ of Cs-7SB, $3 \mathrm{mM}$ of Gua, and $1.5 \mathrm{mM}$ of TOA in Isopar L was equilibrated at 10 ${ }^{\circ} \mathrm{C}$ by end-over-end rotation in a refrigerated incubator with aqueous simulant SRS-45 (O:A = 1:5) for at least $30 \mathrm{~min}$. The equilibrated tube was then centrifuged at $10{ }^{\circ} \mathrm{C}$ and examined visually for evidence of a third phase, usually seen as a thin, viscous drop or layer at the liquid-liquid interface.

Cesium ESS distribution ratios with simulants were obtained by procedures described in detail previously [1]. Typically, polypropylene micro-tubes were mounted by clips on a disk that was rotated for 30 minutes in a constant-temperature incubator or air-box. After the contacting period, the tubes were centrifuged for 5 minutes at 3000 RPM at the experimental temperature. An appropriate aliquot of each phase was subsampled and counted using a Packard Cobra II Auto-Gamma counter. Samples were run in duplicate, and averages are presented. Duplicate agreement was within $\pm 7 \%$ ( $\pm 3 \%$ average precision) for extraction, scrubs, and first strip; $\pm 10 \%$ ( $\pm 7 \%$ average precision) for the second strip; and $\pm 19 \%$ ( $\pm 9 \%$ average precision) for the third strip. 
For density measurements, solvents were stored at $25{ }^{\circ} \mathrm{C}$ (air-box) for three days along with empty 1 or 2 $\mathrm{mL}$ volumetric flasks. The solvents were not washed, as it was demonstrated that washing did not have any impact on the density measurement at the modest precision of the measurements. Volumetric flasks were exposed to room temperature only for the time needed for weighing. They were filled with solvent inside the constant-temperature air-box. Some experiments were duplicated, either with same volume volumetric flasks or with different volumes. Experimental accuracy is estimated to be $\pm 0.012 \mathrm{~g} / \mathrm{mL}$ mainly according to the tolerance of the volumetric glassware, though duplicate precision was much better. 



\section{RESULTS AND DISCUSSION}

\subsection{DETERMINATION OF LIMIT FOR BLENDING RATIOS}

An initial problem was to show that it is possible to prepare the blended solvent using a concentrated solution of NG-CSSX components in Isopar L (called NG-CSSX concentrate). For performance equivalent to NG-CSSX solvent [1], the final concentration of the blend solvent must be $50 \mathrm{mM}$ of total

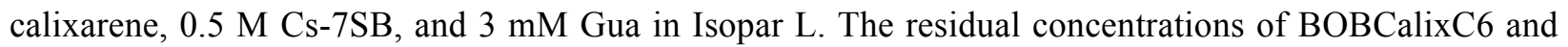
TOA will be small and dictated by the proportion of CSSX solvent used in the mixture. It may be seen from Eqs. 1 and 2 that the NG-CCSX concentrate must employ a higher concentration of MaxCalix and lower concentration of Cs-7SB modifier than the target concentrations in the blended solvent:

MaxCalix concentration $(\mathrm{M})$ in NG-CSSX concentrate $=\left(0.05-0.007 F_{\mathrm{V}}\right) /\left(1-F_{\mathrm{V}}\right)$

Cs-7SB concentration $(\mathrm{M})$ in NG-CSSX concentrate $=\left(0.5-0.75 F_{\mathrm{V}}\right) /\left(1-F_{\mathrm{V}}\right)$

where $F_{\mathrm{V}}$ is the volume fraction of the used MCU CSSX solvent in the blended solvent, assuming the additivity of solvent volumes and additivity of MaxCalix and BOBCalixC6 concentrations. Since the role of the modifier is in part to increase the solubility of the calixarene, it was therefore not certain initially that a homogeneous NG-CSSX concentrate solution could be prepared for a target $50 \% \mathrm{CSSX} / 50 \%$ NGCSSX v/v concentrate $\left(F_{\mathrm{V}}=0.5\right)$ blend.

Initial experiments tested the solubility limits of an NG-CSSX concentrate to be mixed with the used MCU CSSX solvent. Although a nominal $50 \% \mathrm{CSSX} / 50 \% \mathrm{NG-CSSX} v / \mathrm{v}$ concentrate $\left(F_{\mathrm{V}}=0.5\right)$ blend is of primary interest, it was also a goal to find a practical upper limit to the NG-CSSX concentrate to accommodate blends with higher vol\% of used CSSX solvent. Setting the Cs-7SB concentration in the NG-CSSX concentration at zero and solving for $F_{\mathrm{V}}$ in Eq. 2 fixes the upper bounding ratio of the blend at $67 \% \mathrm{CSSX} / 33 \% \mathrm{NG}-\mathrm{CSSX} \mathrm{v} / \mathrm{v}$ concentrate $\left(F_{\mathrm{V}}=0.67\right)$, for which the concentrate has $136 \mathrm{mM}$ MaxCalix. However, for pure unmodified Isopar L, the solubility of MaxCalix in Isopar L is limited to about $35 \mathrm{mM}$, and Gua is sparingly soluble. Thus, some Cs-7SB must be present in the NG-CSSX concentrate to solubilize MaxCalix and Gua, and the practical blend ratio will not reach the bounding ratio.

In a first test, an NG-CSSX concentrate containing $100 \mathrm{mM}$ of MaxCalix, $0.25 \mathrm{M}$ of Cs-7SB, and $6 \mathrm{mM}$ of Gua in Isopar L was prepared. (This conservatively ignores the contribution of BOBCalixC6, which would allow the MaxCalix concentration to be set at $93 \mathrm{mM}$ according to Eq. 1.) No problems of 
dissolution were encountered under ambient conditions. Moreover, the solvent was left over one week in a refrigerator at a temperature of $6^{\circ} \mathrm{C}$ and did not show any sign of third-phase formation. Thus, an NGCSSX concentrate has no solubility issues for making up a 50\% CSSX/50\% NG-CSSX v/v concentrate blend $\left(F_{\mathrm{V}}=0.5\right)$.

A second NG-CSSX concentrate containing $125 \mathrm{mM}$ of MaxCalix, $0.125 \mathrm{M}$ of Cs-7SB, and $7.5 \mathrm{mM}$ of Gua in Isopar L was also readily made under ambient conditions and also did not show any sign of thirdphase formation at $10{ }^{\circ} \mathrm{C}$. Thus, an NG-CSSX concentrate could be used for makeup of a $60 \%$ CSSX $/ 40 \%$ NG-CSSX v/v concentrate blend $\left(F_{\mathrm{V}}=0.6\right)$. This blend ratio likely represents a good upper limit with a comfortable margin before solubility risk is encountered.

A third NG-CSSX concentrate containing $148.5 \mathrm{mM}$ of MaxCalix and $50 \mathrm{mM}$ of Cs-7SB in Isopar L (no Gua included) was prepared, so that a $65 \%$ CSSX/35\% NG-CSSX v/v concentrate blend could be considered if needed. However, this very concentrated solution must be supersaturated, as it showed signs of precipitation after about one week at room temperature.

The results support a simple blending strategy by making up an NG-CSSX concentrate solution with up to $125 \mathrm{mM}$ MaxCalix, allowing a blend of up to $60 \% \mathrm{CSSX} / 40 \% \mathrm{NG}-\mathrm{CSSX} \mathrm{v} / \mathrm{v}$ concentrate $\left(F_{\mathrm{V}} \leq 0.6\right)$. For the target $50 \% \mathrm{CSSX} / 50 \%$ NG-CSSX v/v concentrate blend $\left(F_{\mathrm{V}}=0.5\right)$, it is recommended to mix equal volumes of CSSX solvent and an NG-CSSX concentrate having the following composition: $93 \mathrm{mM}$ of MaxCalix, $0.25 \mathrm{M}$ of Cs-7SB, and $6 \mathrm{mM}$ of Gua in Isopar L. Accounting for the residual BOBCalixC6 in the used CSSX solvent, the final blended composition is therefore $46.5 \mathrm{mM}$ of MaxCalix, $3.5 \mathrm{mM}$ of BOBCalixC6, 0.5 M of Cs-7SB, $3 \mathrm{mM}$ of Gua, and $1.5 \mathrm{mM}$ of TOA in Isopar L.

\subsection{SOLVENT COMPOSITIONS EXAMINED}

It was desired to show that a solvent composition corresponding to the target $50 \% \mathrm{CSSX} / 50 \% \mathrm{NG}-\mathrm{CSSX}$ $\mathrm{v} / \mathrm{v}$ concentrate blend $\left(F_{\mathrm{V}}=0.5\right)$ behaves equivalently to NG-CSSX solvent under NG-CSSX flowsheet conditions at $25{ }^{\circ} \mathrm{C}$ as described earlier [1]. The test was extended to include different NG-CSSX compositions expected if Isopar L content varies, either by evaporation or overcompensation during reconstitution. In addition to these solvents, a "true mix" solvent was prepared using CSSX solvent mixed in equal volume with a solvent containing $93 \mathrm{mM}$ of MaxCalix, $0.25 \mathrm{M}$ of Cs-7SB, and $6 \mathrm{mM}$ of Gua in Isopar L. This will provide a direct comparison with the Blend sample wherein constituents were weighed-in separately. Prior to use, all solvents were washed as described in the Experimental Section above. The solvent compositions used are given in Table 1. 
Table 1. Solvent Compositions Examined

\begin{tabular}{|c|c|c|c|c|c|}
\hline \multirow[t]{2}{*}{ Component } & \multicolumn{5}{|c|}{ Composition } \\
\hline & $\mathrm{NG}^{-\mathrm{CSSX}^{a, b}}$ & $\begin{array}{c}\text { Blend }^{b} \text { or True } \\
\text { Mix }^{c}\end{array}$ & Blend $+10 \%{ }^{b}$ & Blend $+20 \%{ }^{b}$ & Blend $-10 \%{ }^{b}$ \\
\hline BOBCalixC6 & - & $3.5 \mathrm{mM}$ & $3.85 \mathrm{mM}$ & $4.2 \mathrm{mM}$ & $3.15 \mathrm{mM}$ \\
\hline MaxCalix & $50 \mathrm{mM}$ & $46.5 \mathrm{mM}$ & $51.15 \mathrm{mM}$ & $55.8 \mathrm{mM}$ & $41.85 \mathrm{mM}$ \\
\hline Cs-7SB & $0.5 \mathrm{M}$ & $0.5 \mathrm{M}$ & $0.55 \mathrm{M}$ & $0.60 \mathrm{M}$ & $0.45 \mathrm{M}$ \\
\hline TOA & - & $1.5 \mathrm{mM}$ & $1.65 \mathrm{mM}$ & $1.8 \mathrm{mM}$ & $1.35 \mathrm{mM}$ \\
\hline Gua & $3.0 \mathrm{mM}$ & $3.0 \mathrm{mM}$ & $3.3 \mathrm{mM}$ & $3.6 \mathrm{mM}$ & $2.7 \mathrm{mM}$ \\
\hline
\end{tabular}

\subsection{THIRD-PHASE TEST RESULTS}

A sample solvent with the Blend composition shown in Table 1 was equilibrated at $10{ }^{\circ} \mathrm{C}$ with aqueous SRS-45 simulant at $\mathrm{O}: \mathrm{A}=1: 5$. Upon centrifugation at $10{ }^{\circ} \mathrm{C}$, no sign of third phase was observed. Since potassium is the component most associated with third-phase formation [5] and a low O:A ratio was employed, the test is considered bounding, and thus, no third-phase issues are expected for a $50 \%$ CSSX/50\% NG-CSSX v/v concentrate blend.

It should be noted that under similar conditions, a third phase was noted at $13{ }^{\circ} \mathrm{C}$ for a blend composition (46 mM of MaxCalix, $4 \mathrm{mM}$ of BOBCalixC6, 0.5 M of Cs-7SB, and $3 \mathrm{mM}$ Gua in Isopar L) in contact with SRS-45 simulant [1]. The slightly higher BOBCalixC6 concentration in this solvent composition corresponds approximately to a $60 \% \mathrm{CSSX} / 40 \% \mathrm{NG-CSSX} \mathrm{v} / \mathrm{v}$ concentrate blend. A lower operating temperature bound of $12{ }^{\circ} \mathrm{C}$ was targeted in CSSX development [5], and thus, use of $60 \% \mathrm{CSSX} / 40 \%$ NG-CSSX v/v concentrate blend would require a slight compromise in the lower temperature bound. Given that temperature control of $23 \pm 3{ }^{\circ} \mathrm{C}$ has been implemented in the MCU extraction section [1], however, there would appear to be no third-phase issue in actuality.

\subsection{EXTRACTION RESULTS}

Batch ESS test results shown in Table 2 confirm that blended solvent performs approximately equivalently to NG-CSSX solvent. The average for Baseline NG-CSSX, Blend, and True Mix is $50.3 \pm$ 3.6. Relative to a nominal experimental error of 5-10\% in such experiments [5], there is no discernible real difference in cesium distribution behavior.

The ESS results for variation in solvent concentration show that the cesium distribution ratios are 
modestly sensitive to loss or addition of Isopar L diluent. Overall, there appear to be no issues over the range of solvent concentration factors tested, 0.9-1.2, where solvent concentration factor is defined as the total calixarene concentration in the solvent divided by that in the Blend composition as a reference (50 $\mathrm{mM}$ ). Scrubbing and stripping function well in any case. Under dilution conditions (solvent concentration factor $=0.9$ ), the $D_{\mathrm{Cs}}$ value on extraction falls to 44.9 , which when aggravated by a high potassium concentration (not tested) could possibly pose a risk to assuring a DF of $\geq 40,000$, depending on the contactor stage efficiencies and other performance factors.

Log-log plots of $D_{\mathrm{Cs}}$ vs solvent concentration factor for extraction, scrubbing, and stripping show a good linear dependence (Figure 1). Linear-regression parameters corresponding to the line segments shown in the plots are given in Table 3. Surprisingly precise fits as given by the standard errors of fitting and correlation coefficients $\left(r^{2}\right)$ reflect scatter about the lines on the order of the experimental error of the data. It may be seen that the power dependence as given by the slopes increases from extraction to scrubbing and stripping. The cesium distribution ratio is known to obey an approximate first-power dependence on calixarene concentration [4], and thus, the higher observed power dependences in Table 3 reflect the combined effects of calixarene and modifier concentration changing in the same proportion. The greater power dependences of scrubbing and stripping may reflect a cascade effect. For example, increasing $D_{\mathrm{Cs}}$ with concentration factor also means increased potassium concentration, which means greater transfer of nitrate and hydroxide into the scrub section, with corresponding enhancement of $D_{\mathrm{Cs}}$. On the other hand, the slope on extraction may be somewhat suppressed by higher loading of potassium as the solvent becomes more concentrated. 
Table 2. Extract/Scrub/Strip Batch Results ${ }^{a}$

\begin{tabular}{|c|c|c|c|}
\hline \multirow[t]{2}{*}{ Stage } & \multicolumn{3}{|c|}{ Cesium Distribution Ratio $\left(D_{\mathrm{Cs}}\right)$} \\
\hline & NG-CSSX & Blend & True Mix \\
\hline Extraction & 46.2 & 51.9 & 52.9 \\
\hline Scrub 1 & 2.20 & 2.34 & 2.30 \\
\hline Scrub 2 & 0.90 & 0.95 & 0.97 \\
\hline Strip 1 & $1.21 \times 10^{-3}$ & $1.65 \times 10^{-3}$ & $1.74 \times 10^{-3}$ \\
\hline Strip 2 & $2.13 \times 10^{-4}$ & $2.02 \times 10^{-4}$ & $2.23 \times 10^{-4}$ \\
\hline Strip 3 & $1.40 \times 10^{-4}$ & $2.10 \times 10^{-4}$ & $1.75 \times 10^{-4}$ \\
\hline
\end{tabular}

\begin{tabular}{|c|c|c|c|}
\hline \multirow[t]{2}{*}{ Stage } & \multicolumn{3}{|c|}{ Cesium Distribution Ratio $\left(D_{\mathrm{Cs}}\right)$} \\
\hline & Blend $+20 \%$ & Blend $+10 \%$ & Blend $-10 \%$ \\
\hline Extraction & 68.0 & 58.7 & 44.9 \\
\hline Scrub 1 & 3.66 & 2.97 & 1.75 \\
\hline Scrub 2 & 1.40 & 1.17 & 0.76 \\
\hline Strip 1 & $2.78 \times 10^{-3}$ & $2.13 \times 10^{-3}$ & $1.19 \times 10^{-3}$ \\
\hline Strip 2 & $2.94 \times 10^{-4}$ & $2.70 \times 10^{-4}$ & $1.58 \times 10^{-4}$ \\
\hline Strip 3 & $2.97 \times 10^{-4}$ & $2.37 \times 10^{-4}$ & $1.32 \times 10^{-4}$ \\
\hline
\end{tabular}

${ }^{a}$ Tests were run at $25^{\circ} \mathrm{C}$ with SRS- 15 simulant for extraction (O:A $\left.=1: 4\right), 25 \mathrm{mM} \mathrm{NaOH}$ for scrubs $(\mathrm{O}: \mathrm{A}=3.75: 1)$, and $10 \mathrm{mM}$ boric acid for strips $(\mathrm{O}: \mathrm{A}=3.75: 1)$, as recommended previously [1]. Solvent compositions are given in Table 1.

Table 3. Linear Regression Parameters for Dependence of Cesium Distribution Ratio on Solvent Concentration Factor ${ }^{\text {a }}$

\begin{tabular}{lllccc}
\hline \multicolumn{1}{c}{ Stage } & \multicolumn{1}{c}{ Slope } & Intercept & $\boldsymbol{r}^{\mathbf{2}}$ & Std Error & \%Error \\
\hline Extraction & $1.425(57)$ & $1.7155(28)$ & 0.9969 & 0.0053 & $1.2 \%$ \\
Scrub 1 & $2.562(59)$ & $0.3642(29)$ & 0.9990 & 0.0055 & $1.3 \%$ \\
Scrub 2 & $2.130(15)$ & $-0.0216(8)$ & 0.9999 & 0.0014 & $0.3 \%$ \\
Strip 1 & $2.923(58)$ & $-2.7883(29)$ & 0.9992 & 0.0054 & $1.2 \%$ \\
Strip 2 & $2.26(27)$ & $-3.691(14)$ & 0.9720 & 0.0253 & $5.8 \%$ \\
Strip 3 & $2.68(45)$ & $-3.728(23)$ & 0.9463 & 0.0421 & $9.7 \%$ \\
\hline
\end{tabular}

${ }^{a}$ Data from Table 2 were converted to logarithms before performing unweighted linear regression using the LINEST function in an Excel spreadsheet. Line segments are shown in Figure 1. Statistics have the usual meaning in linear least-squares analysis, except \%Error represents the standard error (Std Error) expressed as a percent (Std Error *2.303*100\%). 


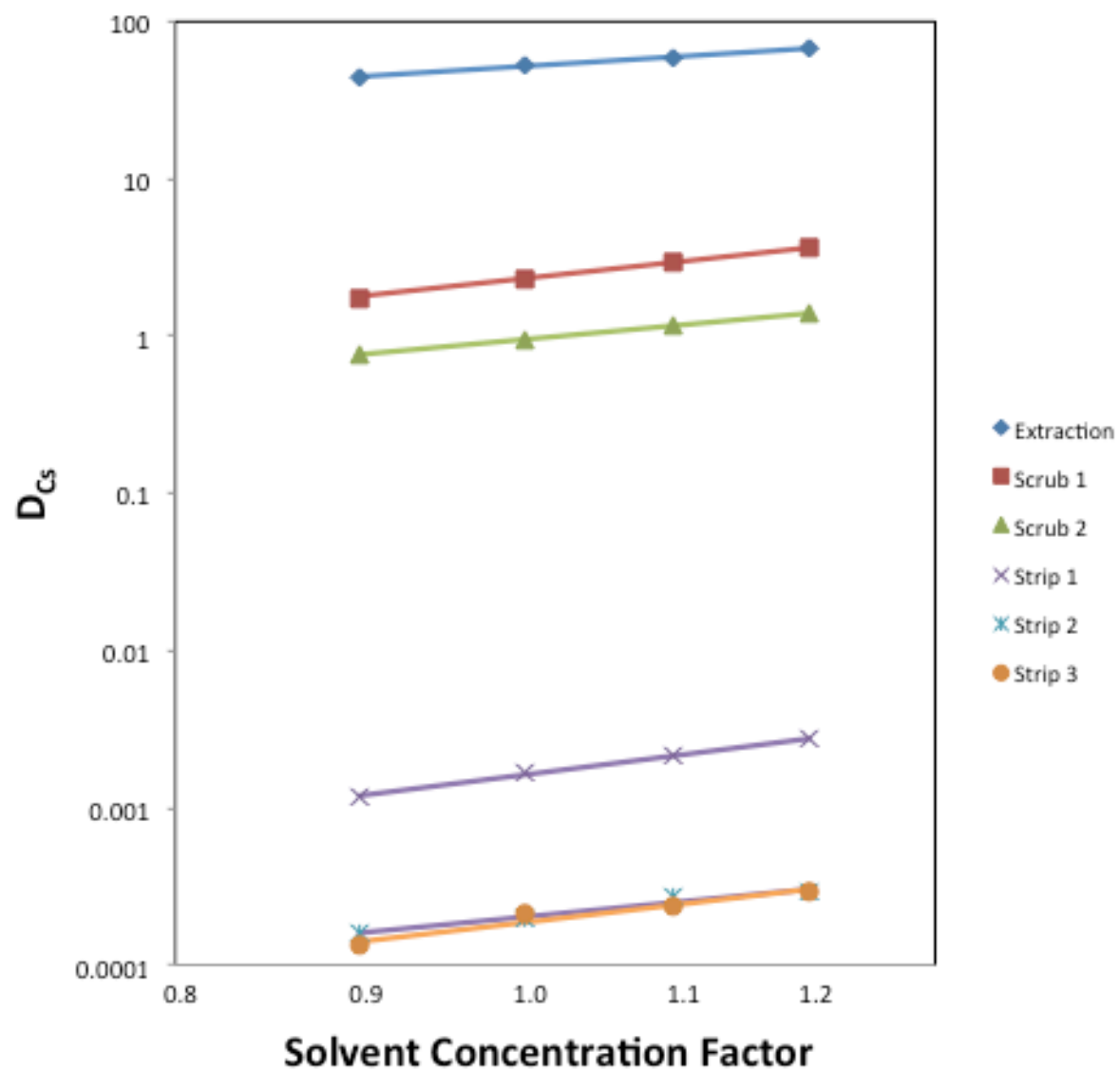

Fig. 1. Cesium distribution ratio plotted vs solvent concentration factor. The Blend composition corresponds to the reference value 1.0. Axes are shown on a log-log scale. Data points are taken from Table 2. Straight line segments are from linear regression as shown in Table 3.

\subsection{DENSITY MEASUREMENTS}

Density results are presented in Table 4 . The average for the NG-CSSX duplicates was $0.8396 \pm 0.0014$ $\mathrm{g} / \mathrm{mL}$, statistically about the same as that for the average of the Blend and True Mix, $0.8373 \pm 0.0016$ $\mathrm{g} / \mathrm{mL}$. As expected, density increases as the concentration of the solvent increases, which should allow the solvent concentration to be monitored. 
Table 4. Solvent Densities

\begin{tabular}{lccc}
\hline Solvent & Mass $(\mathbf{g})$ & Volume $(\mathbf{m L})$ & ${ }^{\mathbf{a}}$ Density $(\mathbf{g} / \mathbf{m L})$ \\
\hline NG-CSSX & 1.6772 & 2 & 0.8386 \\
NG-CSSX (duplicate) & 1.6812 & 2 & 0.8406 \\
Blend & 0.8362 & 1 & 0.8362 \\
True Mix & 0.8384 & 1 & 0.8384 \\
Blend - 10\% & 1.6663 & 2 & 0.8332 \\
Blend + 10\% & 1.7003 & 2 & 0.8502 \\
Blend + 20\% & 1.7119 & 2 & 0.8560 \\
Blend + 20\% (duplicate) & 0.8576 & 1 & 0.8576 \\
\hline
\end{tabular}

${ }^{a}$ Accuracy is estimated to be \pm 0.012 , though precision is much better, as shown by the duplicate agreement. 


\section{CONCLUSIONS}

The results of the present study have validated an equal-volume blending strategy for upgrading freshly prepared CSSX solvent to a blended solvent functionally equivalent to NG-CSSX solvent. Specifically, results show that blending fresh CSSX solvent $(7 \mathrm{mM}$ of BOBCalixC6, $0.75 \mathrm{M}$ of Cs-7SB, and $3 \mathrm{mM}$ of TOA in Isopar L) as currently used in MCU with an equal volume of an NG-CSSX solvent concentrate containing $93 \mathrm{mM}$ of MaxCalix, $0.25 \mathrm{M}$ of Cs-7SB, and $6 \mathrm{mM}$ of Gua in Isopar L yields a blended solvent composition (46.5 mM of MaxCalix, $3.5 \mathrm{mM}$ of BOBCalixC6, 0.5 M of Cs-7SB, $3 \mathrm{mM}$ of Gua, and $1.5 \mathrm{mM}$ of TOA in Isopar L) that exhibits equivalent batch ESS performance to that of the NG-CSSX solvent containing $50 \mathrm{mM}$ of MaxCalix, $0.5 \mathrm{M}$ of Cs-7SB, and $3 \mathrm{mM}$ of Gua in Isopar L. In addition to having extraction properties comparable with NG-CSSX solvent, the equal-volume solvent blend composition is robust to third-phase formation. No solubility issues were encountered regarding preparation of an NG-CSSX concentrate up to $125 \mathrm{mM}$ MaxCalix, higher than that needed for an equalvolume blend. Accordingly, a blend containing up to $60 \% \mathrm{v} / \mathrm{v}$ of CSSX solvent with $40 \% \mathrm{v} / \mathrm{v}$ of a NGCSSX concentrate could be accommodated, though the third-phase formation rises to $13{ }^{\circ} \mathrm{C}$ at the upper bound of potassium concentration in the feed. Extraction and density data for the effect of solvent concentration mimicking diluent evaporation or over-dilution of the equal-volume blended solvent are also given, providing input for setting operational limits.

As pointed out in the Introduction, the experiments described herein employed all pristine solvent components and therefore do not qualify an actual blended solvent starting with used MCU solvent, which can be expected to have undergone at least a minor degree of degradation. Technical risk remains in that impurities in the used MCU solvent may have unanticipated effects in the performance of the NGCSSX flowsheet. Consequently, further work should be considered to evaluate this risk and implement appropriate remediation if needed. 



\section{REFERENCES}

1. B.A. Moyer, P.V. Bonnesen, L.H. Delmau, F.V. Sloop, Jr., N.J. Williams, J.F. Birdwell, Jr., D.L. Lee, R.A. Leonard, S.D. Fink, T.B. Peters, and M.W. Geeting, Development of the NextGeneration Caustic-Side Solvent Extraction (NG-CSSX) Process for Cesium Removal from High-Level Tank Waste-11346, Proceedings Waste Management 2011 Conference, February 27March 3, 2011, Phoenix, AZ; Waste Management Symposia, Tempe, AZ, Paper 11346 (2011).

2. L.H. Delmau, J.F. Birdwell, Jr., P.V. Bonnesen, C.J. Ladd, B.A. Moyer, E.L. Stoner, D.L. Lee, and F.V. Sloop, Jr., Next-Generation Caustic-Side Solvent Extraction (NG-CSSX) Process. Proc. International Solvent Extraction Conference ISEC 2011, Oct. 3-7, 2011, Santiago, Chile; Valenzuela F., Moyer, B. A., Eds.; Gecamin: Santiago, 2011.

3. P.V. Bonnesen, N.C. Duncan, and A. Rajbanshi, Preparation of 1,3-Dicyclohexyl-2(Isotridecyl)guanidine and 1,3-Dicyclohexyl-2-(Isotridecyl)guanidine Hydrochloride (DCITG and DCITG.HCl, Supproessor for Next Generation CSSX Process Solvent. Report ORNL-LTRNGCSSX-007, Oak Ridge National Laboratory, Oak Ridge, TN, April 2011.

4. N. C. Duncan, B. D. Roach, N. J. Williams, P. V. Bonnesen, A. Rajbanshi, B. A. Moyer, N,N'Dicyclohexyl-N'-Isotridecylguanidine as Suppressor for the Next Generation Caustic-Side Solvent Extraction (NG-CSSX) Process, Sep. Sci. Technol. 2012, 47, 2074-2087; DOI: 10.1080/01496395.2012.697517.

5. B.A. Moyer, S.D. Alexandratos, P.V. Bonnesen, G.M. Brown, J.E. Caton, JR., L.H. Delmau, C.R. Duchemin, T.J. Haverlock, T.G. Levitskaia, M.P. Maskarinec, F.V. Sloop, JR., and C.L. Stine, "Caustic-Side Solvent Extraction Chemical and Physical Properties: Progress in FY 2000 and FY 2001,” ORNL/TM-2001/285, Oak Ridge National Laboratory, Oak Ridge, TN, 2002. 